\section{BRAZIULIAN JOURNAL \\ OF MEDICAL AND BIOLOGICAL RLSF.ARCH}

www.bjournal.com.br
ISSN 0100-879X

Volume 42 (11) 993-1118 November 2009.

BIOMEDICAL SCIENCES

AND

CLINICAL INVESTIGATION

Braz J Med Biol Res, November 2009, Volume 42(11)1113-1118

Effects of pneumonectomy on nitric oxide synthase expression and perivascular edema in the remaining lung of rats

M.N. Samano, R. Pazetti, C.M. Prado, I.C. Tibério, P.H.N. Saldiva, L.F.P. Moreira,

P.M. Pêgo-Fernandes, F.B. Jatene and J.C. Das-Neves-Pereira

The Brazilian Journal of Medical and Biological Research is partially financed by
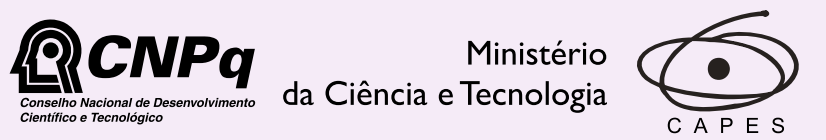

Ministério da Educação

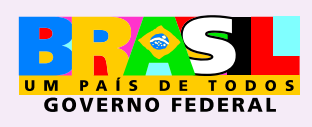

TFAPESP

Institutional Sponsors 


\title{
Effects of pneumonectomy on nitric oxide synthase expression and perivascular edema in the remaining lung of rats
}

\author{
M.N. Samano ${ }^{1}$, R. Pazetti ${ }^{1}$, C.M. Prado ${ }^{2}$, I.C. Tibério ${ }^{2}$, P.H.N. Saldiva ${ }^{3}$, L.F.P. Moreira ${ }^{4}$, \\ P.M. Pêgo-Fernandes ${ }^{1}$, F.B. Jatene ${ }^{1}$ and J.C. Das-Neves-Pereira ${ }^{1}$ \\ ${ }^{1}$ Disciplina de Cirurgia Torácica, ${ }^{2}$ Departamento de Clínica Médica, ${ }^{3}$ Departamento de Patologia, \\ Faculdade de Medicina, Universidade de São Paulo, São Paulo, SP, Brasil \\ ${ }^{4}$ Divisão Cirúrgica, Instituto do Coração, Hospital das Clínicas, Faculdade de Medicina, \\ Universidade de São Paulo, São Paulo, SP, Brasil
}

\begin{abstract}
Pneumonectomy is associated with high mortality and high rates of complications. Postpneumonectomy pulmonary edema is one of the leading causes of mortality. Little is known about its etiologic factors and its association with the inflammatory process. The purpose of the present study was to evaluate the role of pneumonectomy as a cause of pulmonary edema and its association with gas exchange, inflammation, nitric oxide synthase (NOS) expression and vasoconstriction. Forty-two non-specific pathogen-free Wistar rats were included in the study. Eleven animals died during or after the procedure, 21 were submitted to left pneumonectomy and 10 to sham operation. These animals were sacrificed after 48 or $72 \mathrm{~h}$. Perivascular pulmonary edema was more intense in pneumonectomized rats at $72 \mathrm{~h}(\mathrm{P}=0.0131)$. Neutrophil density was lower after pneumonectomy in both groups $(P=0.0168)$. There was higher immunohistochemical expression of eNOS in the pneumonectomy group $(P=$ 0.0208), but no statistically significant difference in the expression of iNOS. The lumen-wall ratio and $\mathrm{pO}_{2} / \mathrm{FiO}_{2}$ ratio did not differ between the operated and sham groups after pneumonectomy. Left pneumonectomy caused perivascular pulmonary edema with no elevation of immunohistochemical expression of iNOS or neutrophil density, suggesting the absence of correlation with the inflammatory process or oxidative stress. The increased expression of eNOS may suggest an intrinsic production of NO without signs of vascular reactivity.
\end{abstract}

Key words: Pneumonectomy; Pulmonary edema; Nitric oxide synthase; Animal models; NOS

\section{Introduction}

Although pulmonary lobectomy is the standard surgical procedure for lung cancer, pneumonectomy is still required in some cases. Central or bulky tumors are examples of complete resection requiring pneumonectomy. Several other inflammatory lung diseases, tuberculosis, bronchiectasis, and other non-malignant conditions may also require this intervention.

In comparison with other surgical procedures, mortality for pneumonectomy is relatively high, ranging from 0 to $9.4 \%(1,2)$. Mortality can be even higher when associated with preoperative chemotherapy (3). The combination with other procedures such as extrapleural pneumonectomy is associated with a mortality rate of 4 to $7 \%(4,5)$. Traumatic injuries requiring emergency pneumonectomy can achieve mortality rates higher than $70 \%$ (6). When compared to pulmonary lobectomy, the mortality rate can increase almost ten-fold (7).
Even though there have been recent improvements in the surgical management with reduction of mortality, the incidence of complications is about $60 \%$. Respiratory complications are the most frequent, and correspond to approximately $15 \%$. In this group of patients, mortality can reach $30 \%$. Among the most relevant complications are acute respiratory failure, pneumonia, pulmonary thromboembolism, and pulmonary edema.

When pulmonary edema occurs after pneumonectomy with no association with pre-existing heart disease, acute pulmonary thromboembolism or an infectious picture, it is called postpneumonectomy pulmonary edema (PPPE) (8-10). Although first reported in patients submitted to pneumonectomy (11), edema can occur after minor resection such as lobectomy and is also recognized as an acute lung injury after

Correspondence: M.N. Samano, Divisão de Cirurgia Torácica, InCor, Av. Dr. Enéas C. Aguiar, 44, $2^{\circ}$ andar, 05403-000 São Paulo, SP, Brasil. E-mail: marcos.samano@incor.usp.br

Research supported by CAPES and CNPq (\#143170/2006-6).

Received January 13, 2009. Accepted September 15, 2009. Available online October 26, 2009. 
pulmonary resection.

Although the pathophysiology of PPPE is not completely known, multifactorial causes seem to be involved in the development of edema, the most probable ones being fluid overload, endothelial damage, increased microvascular permeability, interruption of lymphatic drainage, and increased pulmonary capillary pressure (12). Other possible causes that have been suggested are pulmonary hyperinflation (volutrauma), right ventricular dysfunction, and free radical toxicity (13).

The objective of many studies has been to reproduce experimental pulmonary lesions in animals. Most of these studies have tried to reproduce acute respiratory distress syndrome (ARDS) $(14,15)$. However, there are a few studies, which adequately reproduce PPPE in experimental models (16-18). Developing a PPPE model represents an important step in the understanding of its physiopathology and in the planning of therapeutic measures.

In order to develop a model to determine the effects of left pneumonectomy on the remaining lungs of rats, we hypothesized that 1) pulmonary edema formation occurs after pneumonectomy and this process should be time-dependent, 2) edema formation may be associated with the inflammatory process, with activation and migration of neutrophils to the alveoli septa, 3) this inflammatory process may be associated with the oxidative stress process with an increase in inducible nitric oxide synthase (iNOS), and 4) a decrease in endothelial NOS (eNOS) immunoexpression.

\section{Material and Methods}

Forty-two non-specific pathogen-free Wistar rats weighing on average $300 \mathrm{~g}$ were included in the study. Eleven animals died and were excluded. Thirty-one animals were randomized into four groups: 21 were submitted to pneumonectomy, and 10 to sham operation (control). Of the animals submitted to pneumonectomy, 11 were sacrificed after $48 \mathrm{~h}$, and 10 were sacrificed after $72 \mathrm{~h}$. For the sham-operated control group, 5 rats were sacrificed after 48 and after $72 \mathrm{~h}$.

The animals were sedated and anesthetized with isoflurane in an anesthetic chamber and a tracheal tube was inserted under light laryngoscopy. The animals were submitted to posterolateral thoracotomy through the 5th left intercostal space. The lower pulmonary ligament was released and pneumonectomy was performed through the en bloc ligation of pulmonary hilum elements.

After this procedure, pleural drainage and closure by planes were performed, with the removal of the drain at the end of the procedure. The rats were sent to the animal house and maintained there for 48 to $72 \mathrm{~h}$ depending on the time of sacrifice with food and water ad libitum. No local anesthesia was administered after the procedure. Sham-operated control rats were submitted to thoracotomy as described above, with the lung being manipulated by release of the lower pulmonary ligament. Pleural drainage and closure were performed with the same technique. At the end of the procedure, sham-operated rats were also returned to the animal house and sacrificed after 48 or $72 \mathrm{~h}$.

For the assessment of pulmonary function at 48 and 72 $\mathrm{h}$, the relationship between partial $\mathrm{O}_{2}$ pressure $\left(\mathrm{pO}_{2}\right)$ and inspired $\mathrm{O}_{2}$ fraction $\left(\mathrm{FiO}_{2}\right)$ was determined by gas analysis of arterial blood sample collected just before the sacrifice with $\mathrm{FiO}_{2}$ being always equal to 1.0 .

At the time of sacrifice, the animals were once again sedated and intubated, and submitted to median sternolaparotomy. The abdominal aorta was exposed for arterial blood gas analysis, and the animals were sacrificed by exsanguination via resection of the aorta. The lower right lobe was kept inflated with trapped air by ligation of the corresponding bronchus, fixed in a buffered formaldehyde solution, imbibed for $24 \mathrm{~h}$ and finally sent for histological examination.

Histological sections stained with hematoxylin/eosin (HE) were analyzed in order to quantify pulmonary edema. Digitized images of parenchymal small caliber vessels were analyzed with the UTHSCSA-Image-Tool ${ }^{\circledR}$ software, version 3.0 (19). An index for semi-quantitative quantification of perivascular pulmonary edema (perivascular edema index) was obtained on the basis of the relationship between the perivascular area and the vascular area in question (Figure 1).

Neutrophil density was the criterion chosen to quantify the inflammatory infiltrate. Histological sections stained with $\mathrm{HE}$ were analyzed. A manual count of neutrophils present in the alveolar septa was performed by an observer who did not know the origin of the specimen that was sampled. Twenty non-coincident fields, enlarged to $400 \mathrm{X}$, were quantified by the point-counting technique (20).

Quantification of endothelial isoforms of NOS (iNOS and eNOS) immunostaining was adopted to estimate oxidative stress.

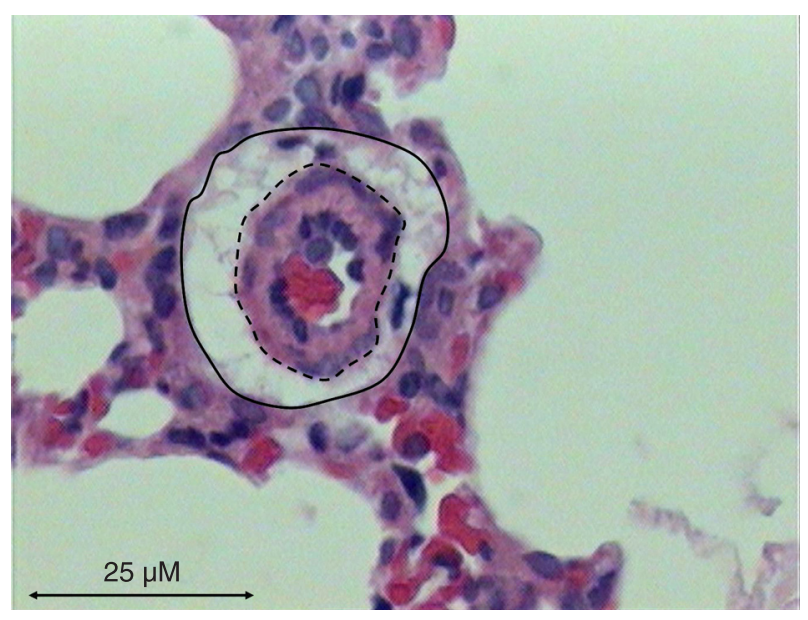

Figure 1. Digitized small caliber vessel with surrounding perivascular edema analyzed with the Image Tool software. The perivascular edema index (PEI) was obtained according to the formula $\mathrm{PEI}=$ perivascular edema area $/$ vessel area. Magnification $=$ 400X; Bar $=25 \mu \mathrm{M}$. 


\section{Immunohistochemistry}

Primary antibodies. The antibodies used were monoclonal antiserum against mouse iNOS (IgG2a - iNOS/NOS type II N32020-BD Transduction Laboratories, USA) and monoclonal antibody for eNOS (\#Rb9279p - Neomarkers, USA).

\section{Immunoexpression quantification}

iNOS immunoexpression quantification. Cells labeled for iNOS in the alveolar septa were counted in 20 non-coincident fields enlarged to $1000 \mathrm{X}$ using the point-counting technique with a reticule of known area, overlaid on the eyepiece of the microscope (21).

eNOS immunoexpression quantification. Endothelial cells of the vascular wall were quantified by analysis of the images using specific software (Image Pro Plus version 4.1, 1998, Media Cybernetics, USA). The total area of the vascular wall and the area with positivity for eNOS were measured in 9 to 10 vessels per animal, enlarged 200X. The percent area positive for eNOS was expressed as the ratio between the positive area for eNOS and the total area of the vascular wall (Figure 2) (22).

Finally, the lumen-wall ratio (L/W ratio) was measured in order to quantify vascular reactivity. It was obtained from vessels adjacent to the alveolar bronchioles with similar diameters. Digital microphotographs of HE-stained histological samples were captured, stored and finally analyzed with the UTHSCSA Image Tool software, version 3.0. The L/W ratio was obtained as the ratio of the vascular lumen areas to the area of the vascular wall in 10 vessels per animal. A decrease in the L/W ratio was considered to be evidence for vasoconstriction (23).

Statistical analysis was performed with the GraphPad software for Windows. Data were analyzed by two-way ANOVA. The results obtained were parametric, and the values are reported as averages with a 95\% confidence interval. The level of significance established for this study was $5 \%$.

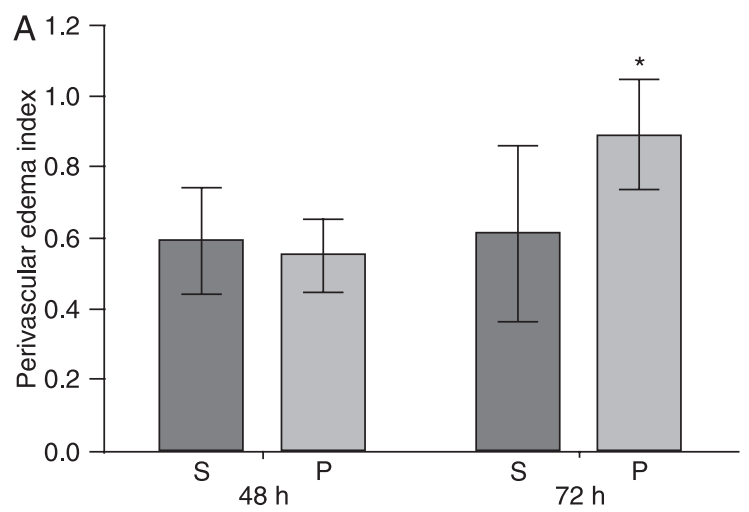

\section{Results}

The average $\mathrm{pO}_{2} / \mathrm{FiO}_{2}$ values for pulmonary function of animals submitted to pneumonectomy and sacrificed after 48 and $72 \mathrm{~h}$ were 302.2 (Cl95\%: 230.7-373.7) and 299.9 (Cl95\%: 244.5-355.2), respectively, while the values for their control groups were 302.7 (Cl95\%: 151-454.3) and 315.7 (Cl95\%: 259.2-372.2). These differences were not statistically significant in terms of the surgery or of the time of sacrifice.

Pneumonectomy did not lead to a significant initial increase (48 h) of perivascular edema when compared to the respective control groups. However, there was an increase in edema throughout $72 \mathrm{~h}(\mathrm{P}=0.0131)$, as shown in Figure 3. A micrograph showing how the perivascular edema is measured is shown in Figure 1.

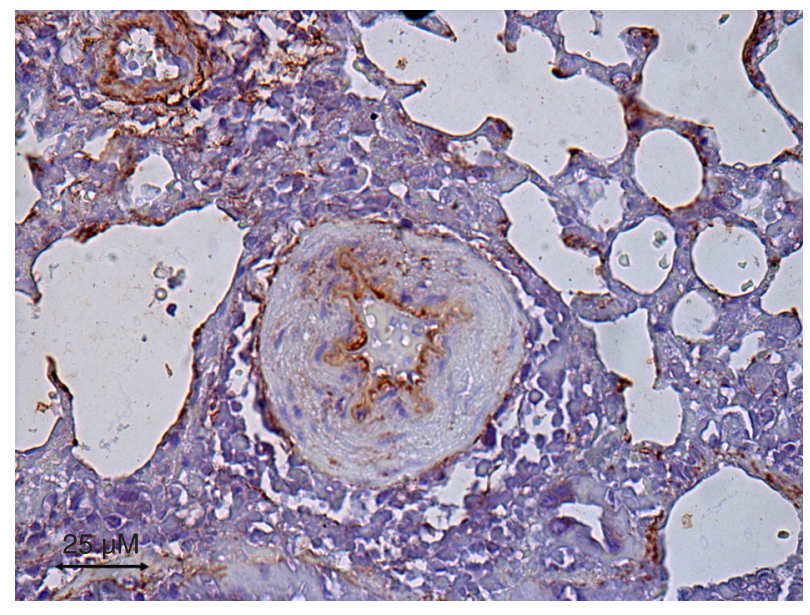

Figure 2. Photomicrograph of a lower right lobe with positive expression of endothelial nitric oxide synthase on the endothelium and surrounding tissue of a small vessel. Magnification = 400X; $\operatorname{Bar}=25 \mu \mathrm{M}$.

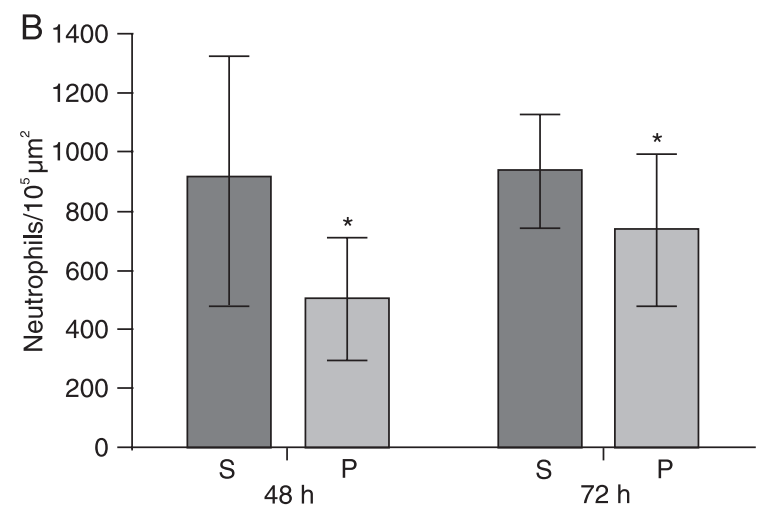

Figure 3. A, Pulmonary edema index graph showing edema formation in rats submitted to pneumonectomy and sacrificed $72 \mathrm{~h}$ after surgery. ${ }^{*} \mathrm{P}<0.05$ compared to all other groups (two-way ANOVA). $B$, Neutrophil density graph representing the reduction of inflammatory infiltration 48 and $72 \mathrm{~h}$ after pneumonectomy. Data are reported as mean $\pm \mathrm{Cl}_{95 \%} . \mathrm{S}=$ sham-operated; $\mathrm{P}=$ pneumonectomy. ${ }^{*} \mathrm{P}<0.05$ compared to control groups (two-way ANOVA). 

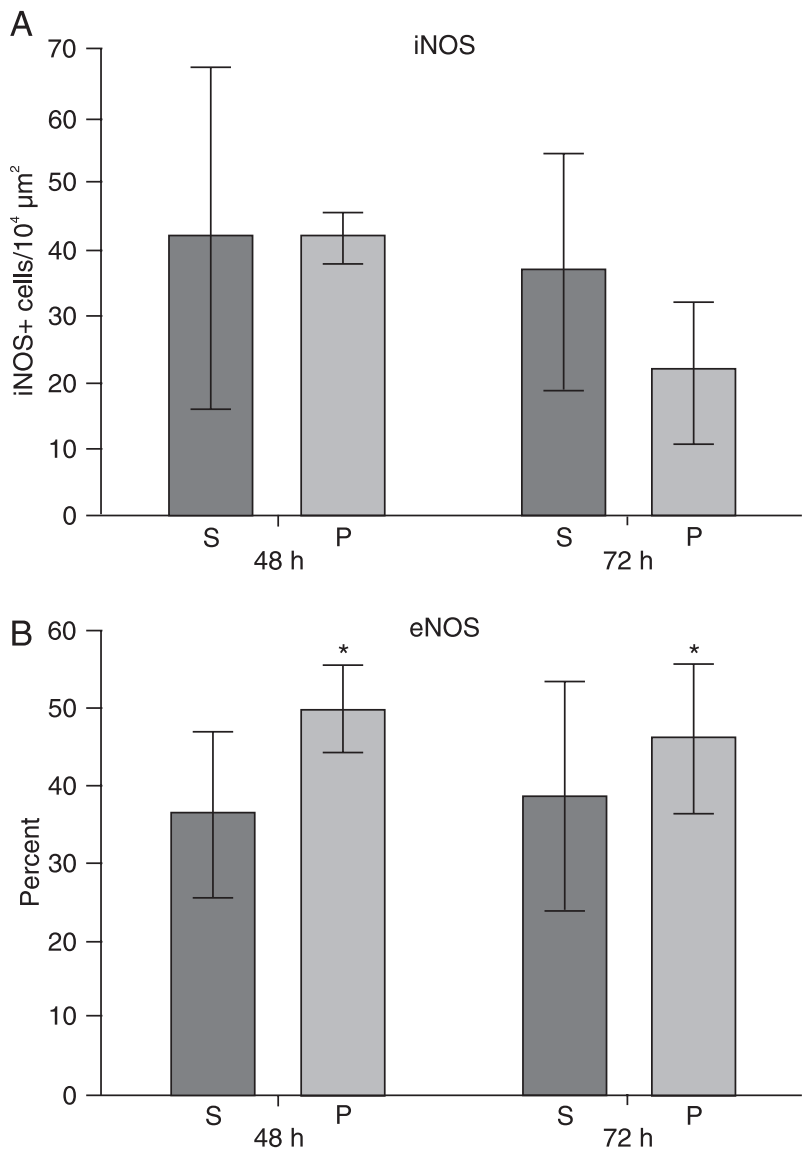

Figure 4. $A$, Inducible nitric oxide synthase (iNOS) expression with lower immunoexpression at $72 \mathrm{~h}$ in both groups. B. Endothelial nitric oxide synthase (eNOS) expression showing an increase in immunoexpression after pneumonectomy. Data are reported as mean $\pm \mathrm{Cl}_{95 \%}$. $\mathrm{S}=$ sham-operated; $\mathrm{P}=$ pneumonectomy. ${ }^{*} \mathrm{P}<$ 0.05 compared to respective control groups (two-way ANOVA).

There was a decrease in neutrophil density in the animals submitted to pneumonectomy and sacrificed 48 and $72 \mathrm{~h}$ after the operation (Figure 3 ).

There was an increase in eNOS expression in the animals submitted to the operation and sacrificed 48 and 72 h later $(P=0.0208)$, as shown in Figure 4. However, we did not observe elevation of iNOS expression after surgery, but rather a decrease of this value at $72 \mathrm{~h}$ in both groups. Figure 2 shows a typical immunohistochemical result with a staining of cells containing eNOS. We observed a decrease of the L/W ratio at $72 \mathrm{~h}$, but no difference between operated and non-operated animals (Figure 5).

\section{Discussion}

The physiological alterations that occur after pneumonectomy in a previously normal individual have not been fully explained. According to clinical studies, the contribution

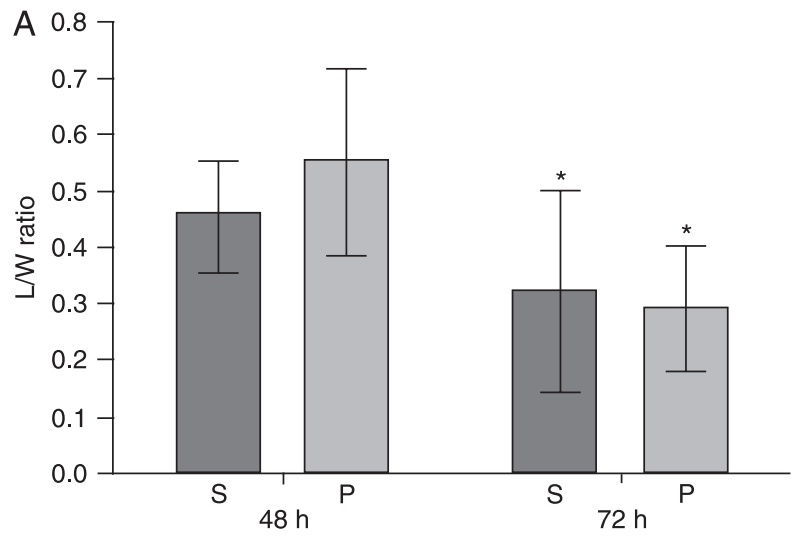

Figure 5. Lumen/wall ratio (L/W ratio) graph showing decreased values at $72 \mathrm{~h}$. Lower values of this index indicate vasoconstriction. Data are reported as mean $\pm \mathrm{Cl} 195 \%$. $\mathrm{S}=$ sham-operated; $\mathrm{P}=$ pneumonectomy. ${ }^{*} \mathrm{P}<0.05$ compared to rats sacrificed after 48 h (two-way ANOVA). No difference was observed between pneumonectomy and control groups.

of the right lung to total pulmonary function is of 53 to $55 \%$ while the contribution of the left lung is 45 to $47 \%$. There is a decrease in lung function after pneumonectomy, and this decrease basically depends on the side of the pneumonectomy, the age of the patient, and the function of the remaining lung. Forced vital capacity (FVC) and forced expiratory volume in $1 \mathrm{~s}\left(\mathrm{FEV}_{1}\right)$ are usually reduced to less than $50 \%$ of the initial value. There is no alteration in arterial oxygen saturation, $\mathrm{pO}_{2}$ or $\mathrm{pCO}_{2}$, but maximum oxygen consumption can decrease from 17 to $28 \%$ after lung resection.

When analyzing the effect of pneumonectomy on postoperative pulmonary function by the $\mathrm{pO}_{2} / \mathrm{FiO}_{2}$ ratio, no loss was observed in the animals submitted to the operation. Even though the analysis was performed with the animals under mechanical ventilation and with inspired $\mathrm{O}_{2}$ fraction equal to 1.0, the decrease in lung parenchyma did not affect this gasometric parameter. However, it should be taken into consideration that the loss of lung parenchyma of rats submitted to left pneumonectomy is even smaller than in humans. In these animals, the left lung only corresponds to $35 \%$ of the total lung mass (24).

In small animals, the perivascular space, formed by capillaries and connective tissue, can present infiltration of leukocytes in several situations, such as inflammatory and allergic reactions. The importance of this space has been long neglected due to the focus on other pulmonary compartments, such as the interstice, the bronchoalveolar space, and the bronchial lamina propria. However, today it is known that the perivascular space is closely related to the accumulation of liquid in pulmonary edema (25-28). In this space, rapid migration of eosinophils is also observed in experimental models of asthma (29). In this model, the histological analysis of the remaining parenchyma showed 
that pneumonectomy causes perivascular pulmonary edema $72 \mathrm{~h}$ after the operation.

Pulmonary edema may result from an isolated inflammatory mechanism in which neutrophils play a significant role. The presence of neutrophils in alveolar tissue is a marker of acute inflammation, in that it is an indirect signal of increased vascular permeability caused by endothelial lesion. To correlate pulmonary edema with an acute inflammatory process, an analysis of the inflammatory infiltrate and of neutrophil density in the alveoli was carried out. However, there was a decrease of this neutrophil infiltrate in the animals submitted to pneumonectomy, indicating that in our case, the perivascular pulmonary edema is not related to an acute inflammatory process.

The activation of neutrophils in inflammatory processes can result in the release of large amounts of free radicals, leading to acute pulmonary lesion. Hydrogen peroxide $\left(\mathrm{H}_{2} \mathrm{O}_{2}\right)$ and nitric oxide (NO) are examples of free radicals involved in pulmonary lesions $(30,31)$. NO is a relaxing factor derived from the endothelium, endogenously formed from L-arginine through the action of enzymes called NOS (32). There are three isoforms of NOS: neuronal NOS, eNOS and iNOS. While the first two are constitutive, the latter is produced by inflammatory stimuli, which result in the sustained production and release of great quantities of NO (33).

There are few studies on the role of NOS isoforms after pneumonectomy. Regarding iNOS, there are no studies that correlate it with the operation and with postpneumonectomy pulmonary edema. However, iNOS is related to acute pulmonary lesion and to ARDS $(34,35)$. Since PPPE is considered to be a variant of ARDS, whose triggering factor is the operation, the operation is expected to cause a possible increase in iNOS levels. According to the technique described by Prado et al. (36), who correlated the histological expression of iNOS with chronic allergic inflammation of the airways, no increase in iNOS was observed in the animals submitted to the operation. Seventy-two hours after the operation, a reduction in tissue expression of this marker was also observed in the animals submitted to the operation, suggesting that oxidative stress is not related to pulmonary edema as a result of the operation.

The adaptation of small caliber vessels in the presence of the pressure alterations caused by pneumonectomy is unknown and could be related to the genesis of PPPE. The increase in pulmonary vascular resistance causes stress on the endothelium and rupture of cell junctions, thus causing extravasation of the liquid to the interstice. Although a reduced L/W ratio was observed at $72 \mathrm{~h}$, there was no difference between operated and non-operated animals. The endothelial fraction of NOS (eNOS) is related to the compensatory growth of the remaining lung after pneumonectomy, and to the vasodilation and normalization of arterial pulmonary pressure $(37,38)$. Even though experimental and clinical studies have not shown a sustained increase in arterial pulmonary pressure after pneumonectomy, this increase occurs during the initial moments after ligation of the pulmonary artery, with the values returning to normal some hours after the procedure. eNOS is responsible for maintaining vascular tonus by means of the release of small quantities of NO. It is produced from the vascular endothelium when submitted to the forces of stress or when receptors such as bradykinin or acetylcholine are activated. In this model, an increase in eNOS expression by means of immunohistochemical tissue expression was observed in the animals submitted to the operation. It may be possible that this elevation contributes to the maintenance of vascular tonus and the L/W ratio after the operation.

Perivascular postpneumonectomy pulmonary edema formation occurs $72 \mathrm{~h}$ after left pneumonectomy in rats but is not associated with an inflammatory infiltrate. Furthermore there is a decrease of iNOS expression suggesting no association with oxidative stress. The increase in tissue expression of eNOS may suggest a protective effect of the endothelium with the production of intrinsic NO to avoid deleterious vasoconstriction.

\section{References}

1. Kopec SE, Irwin RS, Umali-Torres CB, Balikian JP, Conlan AA. The postpneumonectomy state. Chest 1998; 114: 11581184.

2. Bernard A, Deschamps C, Allen MS, Miller DL, Trastek VF, Jenkins GD, et al. Pneumonectomy for malignant disease: factors affecting early morbidity and mortality. J Thorac Cardiovasc Surg 2001; 121: 1076-1082.

3. Martin J, Ginsberg RJ, Abolhoda A, Bains MS, Downey RJ, Korst RJ, et al. Morbidity and mortality after neoadjuvant therapy for lung cancer: the risks of right pneumonectomy. Ann Thorac Surg 2001; 72: 1149-1154.

4. Sugarbaker DJ, Jaklitsch MT, Bueno R, Richards W, Lukanich J, Mentzer SJ, et al. Prevention, early detection, and management of complications after 328 consecutive extrapleural pneumonectomies. J Thorac Cardiovasc Surg 2004; 128: 138-146.

5. Flores RM, Pass HI, Seshan VE, Dycoco J, Zakowski M, Carbone $\mathrm{M}$, et al. Extrapleural pneumonectomy versus pleurectomy/decortication in the surgical management of malignant pleural mesothelioma: results in 663 patients. $J$ Thorac Cardiovasc Surg 2008; 135: 620-626.

6. Baumgartner F, Omari B, Lee J, Bleiweis M, Snyder R, Robertson J, et al. Survival after trauma pneumonectomy: the pathophysiologic balance of shock resuscitation with right heart failure. Am Surg 1996; 62: 967-972.

7. Watanabe S, Asamura H, Suzuki K, Tsuchiya R. Recent results of postoperative mortality for surgical resections in lung cancer. Ann Thorac Surg 2004; 78: 999-1002. 
8. Gibbon JH, Gibbon $\mathrm{MH}$. Experimental pulmonary edema following lobectomy and plasma infusion. Surgery 1942; 12: 694-704.

9. van der Werff YD, van der Houwen HK, Heijmans PJ, Duurkens VA, Leusink HA, van Heesewijk HP, et al. Postpneumonectomy pulmonary edema. A retrospective analysis of incidence and possible risk factors. Chest 1997; 111: 1278-1284.

10. Parquin F, Marchal M, Mehiri S, Herve P, Lescot B. Postpneumonectomy pulmonary edema: analysis and risk factors. Eur J Cardiothorac Surg 1996; 10: 929-932.

11. Zeldin RA, Normandin D, Landtwing D, Peters RM. Postpneumonectomy pulmonary edema. J Thorac Cardiovasc Surg 1984; 87: 359-365.

12. Deslauriers J, Aucoin A, Gregoire J. Postpneumonectomy pulmonary edema. Chest Surg Clin N Am 1998; 8: 611631.

13. Slinger P. Post-pneumonectomy pulmonary edema: is anesthesia to blame? Curr Opin Anaesthesiol 1999; 12: 49-54.

14. Max M, Nowak B, Dembinski R, Schulz G, Kuhlen R, Buell $\mathrm{U}$, et al. Changes in pulmonary blood flow during gaseous and partial liquid ventilation in experimental acute lung injury. Anesthesiology 2000; 93: 1437-1445.

15. Rotta AT, Gunnarsson B, Hernan LJ, Fuhrman BP, Steinhorn DM. Partial liquid ventilation influences pulmonary histopathology in an animal model of acute lung injury. $J$ Crit Care 1999; 14: 84-92.

16. Sakuma T, Sagawa M, Hida M, Nambu Y, Osanai K, Toga H, et al. Time-dependent effect of pneumonectomy on alveolar epithelial fluid clearance in rat lungs. $J$ Thorac Cardiovasc Surg 2002; 124: 668-674.

17. Lee E, Little AG, Hsu WH, Skinner DB. Effect of pneumonectomy on extravascular lung water in dogs. J Surg Res 1985; 38: $568-573$.

18. Williams EA, Quinlan GJ, Anning PB, Goldstraw P, Evans TW. Lung injury following pulmonary resection in the isolated, blood-perfused rat lung. Eur Respir J 1999; 14: 745750.

19. Monteiro R, Jatene FB, Pazetti R, Correia AT, Manoel LA, Bernardo WM, et al. Evaluation of the cardiac morphological alterations secondary to the pulmonary emphysema: experimental study in rats. Braz J Cardiovasc Surg 2004; 19 : 341-347.

20. Finkelstein R, Fraser RS, Ghezzo H, Cosio MG. Alveolar inflammation and its relation to emphysema in smokers. Am J Respir Crit Care Med 1995; 152: 1666-1672.

21. Prado CM, Leick-Maldonado EA, Arata V, Kasahara DI, Martins MA, Tiberio IF. Neurokinins and inflammatory cell iNOS expression in guinea pigs with chronic allergic airway inflammation. Am J Physiol Lung Cell Mol Physiol 2005; 288: L741-L748.

22. Okabe TA, Shimada K, Hattori M, Murayama T, Yokode M, Kita T, et al. Swimming reduces the severity of atherosclerosis in apolipoprotein E deficient mice by antioxidant effects. Cardiovasc Res 2007; 74: 537-545.
23. Batalha JR, Saldiva PH, Clarke RW, Coull BA, Stearns RC, Lawrence J, et al. Concentrated ambient air particles induce vasoconstriction of small pulmonary arteries in rats. Environ Health Perspect 2002; 110: 1191-1197.

24. Brown LM, Rannels SR, Rannels DE. Implications of postpneumonectomy compensatory lung growth in pulmonary physiology and disease. Respir Res 2001; 2: 340-347.

25. Pabst $\mathrm{R}$. The periarterial space in the lung: its important role in lung edema, transplantation, and microbial or allergic inflammation. Pathobiology 2004; 71: 287-294.

26. Pabst R, Tschernig T. Perivascular capillaries in the lung: an important but neglected vascular bed in immune reactions? J Allergy Clin Immunol 2002; 110: 209-214.

27. Drake RE, Laine GA, Allen SJ, Katz J, Gabel JC. A model of the lung interstitial-lymphatic system. Microvasc Res 1987; 34: $96-107$

28. Nagai H, Kira S, Mimoto T, Inatomi K, Yoneda R. Sequential changes of perivascular edema cuffs in models of permeability and hemodynamic pulmonary edema. Respiration 1991; 58: 57-61.

29. Schmiedl A, Tschernig T, Luhrmann A, Pabst R. Leukocyte infiltration of the periarterial space of the lung after allergen provocation in a rat asthma model. Pathobiology 2005; 72 : 308-315.

30. Lases EC, Duurkens VA, Gerritsen WB, Haas FJ. Oxidative stress after lung resection therapy: A pilot study. Chest 2000; 117: 999-1003.

31. Jordan S, Mitchell JA, Quinlan GJ, Goldstraw P, Evans TW. The pathogenesis of lung injury following pulmonary resection. Eur Respir J 2000; 15: 790-799.

32. Moncada $S$, Higgs $A$. The L-arginine-nitric oxide pathway. $N$ Engl J Med 1993; 329: 2002-2012.

33. Moncada S, Higgs EA. The discovery of nitric oxide and its role in vascular biology. Br J Pharmacol 2006; 147 (Suppl 1): S193-S201.

34. Farley KS, Wang LF, Razavi HM, Law C, Rohan M, McCormack DG, et al. Effects of macrophage inducible nitric oxide synthase in murine septic lung injury. Am J Physiol Lung Cell Mol Physiol 2006; 290: L1164-L1172.

35. Ren D, Sun R, Wang S. Role of inducible nitric oxide synthase expressed by alveolar macrophages in high mobility group box 1-induced acute lung injury. Inflamm Res 2006; 55: 207-215.

36. Prado CM, Leick-Maldonado EA, Yano L, Leme AS, Capelozzi VL, Martins MA, et al. Effects of nitric oxide synthases in chronic allergic airway inflammation and remodeling. Am J Respir Cell Mol Biol 2006; 35: 457-465.

37. Leuwerke SM, Kaza AK, Tribble CG, Kron IL, Laubach VE. Inhibition of compensatory lung growth in endothelial nitric oxide synthase-deficient mice. Am J Physiol Lung Cell Mol Physiol 2002; 282: L1272-L1278.

38. Maxey TS, Fernandez LG, Reece TB, Keeling WB, Kron IL, Laubach VE. Endothelial nitric oxide synthase is essential for postpneumonectomy compensatory vasodilation. Ann Thorac Surg 2006; 81: 1234-1238. 